\title{
CFD model-supported design of monodisperse co-current spray dryers
}

\section{Jaskulski, M. ${ }^{{ }^{*}}$; Tran, T.T.H. ${ }^{\text {b; Tsotsas, E. }}{ }^{c}$}

a Faculty of Process and Environmental Engineering, Lodz University of Technology, Wolczanska Str 213., 95-924 Lodz, Poland.

b School of heat engineering and refrigeration, Hanoi University of Science and Technology, 1st Dai Co Viet, Hanoi, Vietnam.

c Thermal Process Engineering, Otto von Guericke University Universitaetplatz 2, 39106 Magdeburg, Germany.

*E-mail of the corresponding author: maciej.jaskulski@p.lodz.pl

\begin{abstract}
In this study the operation of spray drying chambers fitted by the multi-stream monodisperse atomizer was simulated by the previously developed CFD model of skim milk spray drying. A series of CFD simulations of skim milk monodisperse spray drying were performed. The influence of different nozzle positions, initial droplet diameters $(180 \mu \mathrm{m}$ and $167 \mu \mathrm{m})$ and the way of air introduction (vertical or swirling with $30^{\circ}$ or $60^{\circ}$ angle) on the drying process were checked. Parameters like drying air and particle residence time, wall deposition, inter-particle collisions, protein thermal deactivation, air velocity and temperature profiles were compared for each case.
\end{abstract}

Keywords: CFD, spray drying, skim milk, monodisperse atomizers, optimization. 


\section{Introduction}

Spray drying process for powder production and dehydration is widely used in many sectors of industry. Low content of solids in the liquid feed sprayed inside the drying chamber results in a large amount of energy required for particle solidification and evaporation of moisture. Therefore, the spray drying process consumes much energy used for preparation of the drying agent. Continuous growth in the demand for spray dried products makes improvements in the spray drying process necessary, not only in regard of energy and substrates consumption but also of product quality.

Modern technologies of computational simulation allow to design or optimize the production process of powders with properties directly specified by the customers. Spray drying process optimization performed by CFD techniques can also be used to solve production problems in certain regions of the drying chamber. An example has been given by a series of CFD simulations of a detergent counter current spray drying tower performed by Wawrzyniak [1]. In this work a theoretical solution of problems related to powder baking near the hot air inlet area was proposed. Particle deposition on the wall and its effect on spray drying tower operation has been widely studied in the literature [2]. Especially, the effects of flow hydrodynamics and air flow direction on the trajectories of particles, residence time and deposition inside of the drying chamber has been studied [3]. In CFD studies of air hydrodynamics in spray drying towers mostly the effect of different ways of air introduction on flow stability inside of the chamber has been checked [4]. Simulations with swirl air distribution were verified on the basis of experimental investigations [5]. Not only airflow and drying efficiency can be simulated by the CFD models. More advanced studies on particle morphology allow to include into the CFD simulations models of agglomeration, particle formation or material degradation during the spray drying.

Particle agglomeration occurs mostly in counter current and mixed flow spray dryers, having significant influence on particle size distribution in the final product. In some production processes full control of the size of particles in the dried powder is required. For this reason CFD simulations are used to identify theoretically regions where agglomeration can take place [6] or to predict final particle size distribution in the product [7]. In food industry, like skimmed milk powder production, it is also necessary to take into account influence of process parameters on product quality. CFD simulations of the influence of drying parameters on lysine loss were performed for example by Schmitz-Schug [8].

In the presented article the influence of drying conditions, swirl flow, monodisperse multistream atomizer configurations and droplet diameter on the drying efficiency, product quality, agglomeration probability and wall deposition will be predicted by the developed CFD skimmed milk spray drying model. All simulation results are compared to show the impact of each parameter on the drying process and to show which configuration and 
parameters can give optimal results in spray drying of skimmed milk when using novel monodisperse multi-stream atomizers.

\section{Materials and Methods}

The presented manuscript is a summary of the European project ENTHALPY whose task is to optimize skim milk powder production via spray drying. Design of new spray dryer can be supported by the CFD simulations and for this reason mathematical model of skim milk drying and thermal inactivation of the proteins need to be developed.

\subsection{CFD model of skim milk spray drying}

Development of the CFD model of skim milk spray drying process starts with the series of single droplet drying (SDD) experiments performed for milk and milk components in wide range of operating conditions [10]. Based on obtained data advanced model of single droplet drying was developed. This model takes into account internal circulation of liquid in droplet, spatial gradient of solid concentration, temperature and moisture distribution and calculation of inflation and deflection of particle in elevated temperatures [11]. Next developed model was simplified and implemented into the CFD solver. To verify correctness of performed simulations calculation results were compared with experimentally obtained data from the test spray drying installation constructed on Otto von Guericke University in Magdeburg [12]. The test installation will later colled OVGU dryer. Additionally, evaporation model was combined with the protein inactivation model to calculate degradation of the skim milk powder during the spray drying process [13]. A full mathematical description of the models and details of the dryer geometry and settings of the CFD solver can be found in the quoted articles. Here only brief description of CFD simulations is presented.

\subsection{Geometry and nozzle configurations}

Tested spray drying tower is a co-current installation with narrow drying chamber: total height is $6.5 \mathrm{~m}$ with $0.4 \mathrm{~m}$ inner diameter [12]. Instead of a standard two-fluid spray nozzle the newly designed monodisperse multi-stream droplet atomizer was used [14]. It was assumed that dryer will be feeded by four monodisperse atomizers. Each printing head has a base plate with 150 outlets placed in one line. Each outlet generates a single stream of droplets with constant initial diameter which depends on the size of the outlet and on the frequency of the piezo element inside the printing head. In CFD simulations special arrangements of the heads, which lead to a variation in the shape and dimensions of their supporting plates, were tested. Each configuration of the printing heads has a different denotation which will be used further in the description of results:

- CI_1 - four printing heads arranged one next to the other. Heads are mounted on the round base (diameter $214 \mathrm{~mm}$ ) plate used in the OVGU dryer. 
- $\quad$ SQ_2 - four printing heads arranged one beside the other. Heads are mounted on the rectangular (188 $\mathrm{mm}$ x $188 \mathrm{~mm}$ ) base plate.

- RI_3 - four printing heads arranged on a ring support plate (internal diameter $=150 \mathrm{~mm}$, external diameter $=290 \mathrm{~mm}$, distance of printing head from the axis $=80 \mathrm{~mm}$ )

- CR_4 - four printing heads mounted on an equal-armed cross with arms of length $133 \mathrm{~mm}$ and breadth $42 \mathrm{~mm}$.

To distinguish different air inlet directions additional markings were added to the name of the geometry:

- $\mathbf{A x}$ - axial flow of air (example Cl_Ax).

- $\mathbf{3 0}$ - airflow with $30^{\circ}$ swirl (example Cl_30).

- 60 - airflow with $60^{\circ}$ swirl (example Cl_60).

ANSYS Meshing software was used for grid generation. Near the wall area, where the highest gradients of velocity are predicted, a five-step boundary layer was generated. Finally, a fine mesh with 385k tetrahedral elements was generated. For every case, with different printing head configurations, a new mesh was generated with different computational elements on the atomizer support plate and air inlet surface. Those differences change the mesh structure near the air inlet area. However, all mesh quality parameters and number of mesh element were kept constant.

\subsection{Operating parameters}

Skimmed milk with initial solid mass fraction equal to $45 \%$ was used as the feed in the simulations. Initial diameter of the droplets injected into the drying chamber depends on the frequency of the piezo element inside of the printing head. In this report two frequencies were tested, $12 \mathrm{kHz}$ and $15 \mathrm{kHz}$ which generate droplets with diameters of 180 microns and 167 microns respectively. The mass flow rate of skimmed milk solution was equal to $0.018 \mathrm{~kg} / \mathrm{s}$, with an inlet temperature of $55^{\circ} \mathrm{C}$. Initial velocity of the droplets was $18.7 \mathrm{~m} / \mathrm{s}$.

Air inlet on top of the dryer was set up as mass flow inlet boundary condition. In every simulated case the mass flow rate of air was constant and equal to $0.1 \mathrm{~kg} / \mathrm{s}$. Air was assumed as dry ideal gas with initial temperature of $200^{\circ} \mathrm{C}$. In simulations with vertical airflow direction, inlet air vectors were set as normal to the boundary. In simulations with swirl airflow, air direction vectors were inclined to the inlet surface by an angle of $30^{\circ}$ or $60^{\circ}$. Centre of rotation was the tower axis.

To calculate the number of inter-particle collisions it was necessary to perform all calculations in transient state. The number of time steps maintained for every simulation was 400 with time step size of $0.1 \mathrm{~s}$. In simulations with axial flow of air the realizable $k-\varepsilon$ turbulence model was used. However, in simulations with rotary movement of air the turbulence model was changed to the RNG $k-\varepsilon$ turbulence model with switched on option of swirl dominated flow, which is recommended for calculations with rotary airflow. 


\subsection{Simulations results}

Simulations results were summarized in Table 1. Swirling air distribution has a significant impact on particle flow trajectories. Particles rotation increases their residence time inside the drying chamber.

Table 1. Summary of the CFD simulations results

\begin{tabular}{|c|c|c|c|c|c|c|}
\hline \multirow[t]{2}{*}{$\begin{array}{l}\text { Case } \\
\text { study }\end{array}$} & \multicolumn{2}{|c|}{$\begin{array}{c}\text { Particle residence } \\
\text { time, s }\end{array}$} & \multicolumn{2}{|c|}{$\begin{array}{c}\text { Outlet air } \\
\text { temperature, }{ }^{\circ} \mathrm{C}\end{array}$} & \multicolumn{2}{|c|}{$\mathrm{H}_{2} \mathrm{O}$ removed, \% } \\
\hline & $180 \mu \mathrm{m}$ & $167 \mu \mathrm{m}$ & $180 \mu \mathrm{m}$ & $167 \mu \mathrm{m}$ & $180 \mu \mathrm{m}$ & $167 \mu \mathrm{m}$ \\
\hline CI_Ax & 3.08 & 3.23 & 62.61 & 63.01 & 92.32 & 91.93 \\
\hline CI_30 & 3.95 & 4.24 & 64.96 & 63.39 & 95.15 & 98.65 \\
\hline CI_60 & 5.46 & 4.83 & 70.09 & 68.11 & 87.91 & 89.06 \\
\hline SQ_Ax & 2.92 & 3.21 & 62.65 & 63.04 & 93.08 & 98.47 \\
\hline SQ_30 & 3.97 & 4.30 & 62.86 & 63.12 & 98.69 & 98.66 \\
\hline SQ_60 & 6.80 & 4.55 & 68.58 & 67.48 & 95.98 & 96.57 \\
\hline RI_Ax & 3.87 & 4.17 & 63.48 & 63.52 & 98.77 & 98.89 \\
\hline RI_30 & 4.23 & 4.23 & 74.06 & 72.91 & 86.97 & 88.06 \\
\hline RI_60 & 4.76 & 4.51 & 72.8 & 72.27 & 95.56 & 96.17 \\
\hline CR_Ax & 4.24 & 4.24 & 63.57 & 64.15 & 96.25 & 96.69 \\
\hline CR_30 & 6.12 & 5.75 & 66.11 & 65.95 & 97.72 & 98.02 \\
\hline CR_60 & 6.39 & 6.55 & 72.62 & 71.29 & 86.03 & 85.88 \\
\hline \multirow[t]{2}{*}{$\begin{array}{l}\text { Case } \\
\text { study }\end{array}$} & \multicolumn{2}{|c|}{$\begin{array}{c}\text { Probability of } \\
\text { collision, \% }\end{array}$} & \multicolumn{2}{|c|}{$\begin{array}{c}\text { Wall deposition, } \\
\%\end{array}$} & \multicolumn{2}{|c|}{$\begin{array}{c}\text { Protein activity } \\
\text { level, \% }\end{array}$} \\
\hline & $180 \mu \mathrm{m}$ & $167 \mu \mathrm{m}$ & $180 \mu \mathrm{m}$ & $167 \mu \mathrm{m}$ & $180 \mu \mathrm{m}$ & $167 \mu \mathrm{m}$ \\
\hline CI_Ax & 5.27 & 5.13 & 0.47 & 0.42 & 96.05 & 95.83 \\
\hline CI_30 & 2.85 & 1.98 & 0.84 & 0.89 & 94.21 & 94.67 \\
\hline CI_60 & 7.78 & 8.33 & 2.15 & 2.06 & 95.54 & 97.14 \\
\hline SQ_Ax & 5.77 & 4.91 & 0.60 & 0.44 & 91.62 & 95.26 \\
\hline SQ_30 & 1.77 & 1.76 & 0.82 & 0.85 & 94.97 & 94.66 \\
\hline SQ_60 & 8.65 & 8.72 & 2.07 & 2.11 & 96.07 & 97.21 \\
\hline RI_Ax & 5.32 & 5.66 & 0.41 & 0.48 & 90.76 & 94.68 \\
\hline RI_30 & 9.07 & 9.05 & 1.76 & 1.75 & 96.03 & 96.15 \\
\hline RI_60 & 9.47 & 9.26 & 3.30 & 3.41 & 95.00 & 96.02 \\
\hline CR_Ax & 5.88 & 6.56 & 0.44 & 0.45 & 93.51 & 94.56 \\
\hline CR_30 & 3.38 & 3.16 & 1.17 & 1.13 & 96.81 & 96.45 \\
\hline CR_60 & 7.93 & 8.76 & 3.27 & 3.39 & 94.31 & 94.67 \\
\hline
\end{tabular}

Based on the evaporation model, temperature distribution inside the spray dryer was obtained. The temperature of the continuous phase decreases along the tower because the 
heat is transferred to the discrete phase for moisture evaporation. Swirling flow of the air and particles shows an interesting relationship with the temperature drop due to moisture evaporation. Comparison of time average outlet air temperature shows that in cases with higher swirl air movement the final air temperature is higher. This phenomenon can be explained as follows: In cases of axial flow of air particles are falling in the whole volume of the dryer, which results in a low temperature region near to the tower axis. With increasing swirl angle particles are moving to the dryer wall and the low temperature region is also moved from the dryer centre near to the dryer wall. For $60^{\circ}$ swirl angle all particles are flowing near the wall where due to evaporation and heat loses to the environment air temperature is lowest. Due to this, in cases with swirl movement of air the evaporation rate of particle moisture is lower and the overall consumption of energy decreases. From the analysis of changes in evaporation rate of particles following conclusions can be drown:

For vertical flow in cases Cl_1 and SQ_2 where particle injections are concentrated near to the tower axis, the highest concentration of water source terms can be observed in the middle of the drying tower. In RI_3 and CR_4 nozzle configurations particles are better distributed in the volume of the dryer.

Swirling introduction of air significantly changes the pattern of evaporation regions inside the dryer. With axial air flow evaporation takes place in the middle of the dryer. With an increase in the angle of air rotation the centrifugal force that pushes the particle toward the walls of the dryer also increases. Near to the wall evaporation rate is lower due to lower air temperature. However the drying process is much longer, due to longer residence time of particles inside the drying chamber. Analysis of drying efficiency shows that $30^{\circ}$ swirl increases the residence time and this improves drying efficiency. However too strong rotation pushes particles into the low temperature region and decreases drying efficiency.

From the CFD simulations we determined regions, in which inter-particle collisions can take place. With axial air flow particle collision regions are distributed in the whole volume of the drying chamber. With increasing angle of air rotation collision regions are moved to the dryer wall. With small swirl angles $\left(30^{\circ}\right)$ when particles are not reaching the dryer wall, rotary movement decreases the inter-particle collision probability.

Powder deposition on the dryer walls is an undesirable process during spray drying. This phenomenon can reduce the product quality or, in extreme case, stop the drying process by clogging the drying chamber. Analysis of contours where powder can be deposited and overall percentage of feed storage on the dryer wall shows that in such a narrow spray dryer swirling movement of air is not recommended and strongly increases powder deposition on the dryer walls. According to the deactivation model, the two parameters that control the activity of the protein in skimmed milk are moisture content and temperature of particles. From the point of view of protein deactivation analysis, strong swirling movement of air decreases deactivation rate despite the longer residence time of particles inside the drying 
chamber. Near to the wall particles are dried slower in low temperature region which results in lower protein deactivation.

\section{Conclusions}

Series of CFD skimmed milk drying simulations of the co-current spray dryer fitted by multistream monodisperse atomizer were performed. Comparison of obtained simulations results shows:

- The use of monodisperse atomizer allows to obtain a more orderly flow of particles inside the drying chamber than in the simulations with standard polidisperse nozzle.

- Greater spacing between atomizer heads (like in the suggested ring or cross configuration) increases drying efficiency.

- In co-current spray towers with narrow diameter of chamber swirling air flow is not recommended due to:

o Creating centrifugal forces which increase wall deposition and particle collision rate.

o Much energy from the air is not used for the evaporation process. Dryer has lower efficiency.

o Less uniform radial distribution of air velocities and temperatures.

- Dryers with axial movement of air fitted by monodisperse atomizer have lower probability of powder agglomeration and wall deposition than dryer with standard twofluid spray nozzles.

- Powders obtained from dryers with monodisperse atomizers have higher protein activity level than products obtained from standard production.

- $\quad$ Produced powder will have uniform particle size.

Simulation of OVGU dryer shows that for the new monodisperse atomizer the best construction is a high and narrow co-current spray dryer. Axial air flow without recirculation prevents agglomeration, wall deposition and overheating of particles. Co-current spray drying allows for better control by changing flow the rate and temperature of the drying agent. The optimal diameter of the tower depends on the number of installed printing heads. However it is recommended that each printing head should be separated by an air inlet to increase drying efficiency and prevent collisions between the particle streams.

CFD simulations of skimmed milk spray drying feeded by monodisperse atomizer show big advantages over other drying processes performed by standard nozzles. Produced powder is expected to have high quality and uniform particle size which can be of crucial in pharmaceutical, cosmetic and food powders production.

\section{Acknowledgements}

The research leading to these results has received funding from the European Union's Seventh Framework Programme for research, technological development and demonstration under grant agreement $n^{\circ} 613732$ - project ENTHALPY. 


\section{References}

[1] P. Wawrzyniak, M. Podyma, and I. Zbicinski, "Industrial Spray Tower Hot Air Inlets Area Temperature Control,” J. Chem. Eng. Japan, vol. 50, no. 10, pp. 768-774, 2017.

[2] V. Francia, L. Martin, A. E. Bayly, and M. J. H. Simmons, "Influence of wall friction on flow regimes and scale-up of counter-current swirl spray dryers," Chem. Eng. Sci., vol. 134, pp. 399-413, Sep. 2015.

[3] V. Francia, L. Martin, A. E. Bayly, and M. J. H. Simmons, “An experimental investigation of the swirling flow in a tall-form counter current spray dryer," Exp. Therm. Fluid Sci., vol. 65, pp. 52-64, 2015.

[4] C. Lebarbier, T. K. Kockel, D. F. Fletcher, and T. A. G. Langrish, "Experimental Measurement and Numerical Simulation of the Effect of Swirl on Flow Stability in Spray Dryers,” Chem. Eng. Res. Des., vol. 79, no. 3, pp. 260-268, Apr. 2001.

[5] D. B. Southwell and T. A. G. Langrish, "The Effect of Swirl on Flow Stability in Spray Dryers,” Chem. Eng. Res. Des., vol. 79, no. 3, pp. 222-234, Apr. 2001.

[6] L. Malafronte, L. Ahrné, F. Innings, A. Jongsma, and A. Rasmuson, "Prediction of regions of coalescence and agglomeration along a spray dryer-Application to skim milk powder,” Chem. Eng. Res. Des., vol. 104, pp. 703-712, Dec. 2015.

[7] M. Jaskulski, P. Wawrzyniak, and I. Zbiciński, "CFD Model of Particle Agglomeration in Spray Drying,” Dry. Technol., vol. 33, no. 15-16, pp. 1971-1980, 2015.

[8] I. Schmitz-Schug, U. Kulozik, and P. Foerst, "Modeling spray drying of dairy products - Impact of drying kinetics, reaction kinetics and spray drying conditions on lysine loss," Chem. Eng. Sci., vol. 141, pp. 315-329, Feb. 2016.

[9] P. Wawrzyniak, A. Polańczyk, I. Zbicinski, M. Jaskulski, M. Podyma, and J. Rabaeva, “Modeling of Dust Explosion in the Industrial Spray Dryer,” Dry. Technol., vol. 30, no. 15, pp. 1720-1729, Dec. 2012.

[10] T. T. H. Tran, J. G. Avila-Acevedo, and E. Tsotsas, "Enhanced methods for experimental investigation of single droplet drying kinetics and application to lactose/water,” Dry. Technol., vol. 34, no. 10, pp. 1185-1195, Jul. 2016.

[11] T. T. H. Tran, M. Jaskulski, J. G. Avila-Acevedo, and E. Tsotsas, "Model parameters for single-droplet drying of skim milk and its constituents at moderate and elevated temperatures,” Dry. Technol., vol. 35, no. 4, pp. 444-464, Mar. 2017.

[12] T. T. H. Tran, M. Jaskulski, and E. Tsotsas, "Reduction of a model for single droplet drying and application to CFD of skim milk spray drying.," Dry. Technol., vol. in press., 2017.

[13] M. Jaskulski, J. C. Atuonwu, T. T. H. Tran, A. G. F. Stapley, and E. Tsotsas, "Predictive CFD modeling of whey protein denaturation in skim milk spray drying powder production,” Adv. Powder Technol., 2017.

[14] H. van Deventer, R. Houben, and R. Koldeweij, "New Atomization Nozzle for Spray Drying,” Dry. Technol., vol. 31, no. 8, pp. 891-897, Jun. 2013. 